\title{
The best companies bare all
}

\author{
Tom Jacobs
}

There are many indicia of a shareholderfriendly biopharmaceutical company, but one is crucial: the ease with which an investor can understand the drug development pipeline and its chance of producing future wealth. The traditional strategy for an investor intent on discovering such details was to comb annual and quarterly company reports. Yet with web development and design cheaper and better every day, it is a mystery why more company websites do not provide clearer key pipeline information upfront.

At minimum, a satisfactory company website should identify drugs and indications, trial status, trial results, and any shared drug ownership. Without this information, it's impossible to understand market size, competition, chances of success, and investor share of the wealth, all of which help an investor balance investments and decide to buy or sell.

\section{Getting there}

Not all biotech drug makers make it easy for you to find their pipelines. Some place the word front and center, whereas others make you search. Why bury the truth? Are they embarrassed? Award one point for 'pipeline,' with a bonus to Élan Pharmaceuticals (Dublin, Ireland; NYSE:ELN). That company's "View Our Pipeline" (http://www.elan.com/) grabs you immediately with its simple and clear graphic.

\section{Drugs, indications, market size}

At minimum, you want the chemical name and trade name, if any, as well as the specific indication being tested, with products on the market and in development joined in an easyto-read chart. This is central to web searches to find competition and evaluate market size.

The greatest crimes occur with indications. 'Prostate cancer' tells you something, but 'hor-

Tom Jacobs is cofounder of Complete Growth Investor (http://www.completegrowth.com). He welcomes your comments at tom@completegrowth.com. Tom owns no shares of companies mentioned in this article. monally responsive' or 'hormone-independent' better define the market-kudos to Praecis Pharmaceuticals (Waltham, Mass., USA; Nasdaq:PRCS; http://www.praecis.com /rd/index.html). 'Cardiovascular,' 'oncology,' and 'metabolic disease' are all but useless.

Headed in the right direction again is Élan, which provides a drug 'Fact Sheet' (e.g., http:// www.elan.com/research_development/Antegren/) that defines indications clearly and in most cases identifies the market size in detail. One quibble: the best information is for drugs currently marketed and in trials for other indications, with no Fact Sheets for unapproved drugs in early stages.

Why don't company websites tell you about competing drugs? Because they are public relations tools, parables to boost the stock price. This is short-sighted at best.

\section{Trial status}

The typical company's pipeline web page offers a sideways bar chart with progress through preclinical, clinical phases 1,2 and 3, and marketing approval. Most US company sites are far too US-centric, failing to identify whether the regulatory status provided is for the United States, European Union or other markets. Why should you, as a current or prospective part owner of a business, have to work for this? Why shouldn't companies compete to raise the bar?

Award bonus points for charts that show part progress as well as 'filed' and 'phase 4' or 'post-approval,' and that tag the status a bit more with 'enroll,' 'initiate,' or 'complete,' with more available with a click. Scoring high are Amgen (Thousand Oaks, Calif., USA; Nasdaq:AMGN; http://www.amgen.com/rnd /pipeline.html) and Élan, whose chart adds 'discovery' and whose delicious Fact Sheets select and provide headline links to all press releases relevant to the drug.

\section{Trial results}

In this essential area, a few comments in a press release don't cut the mustard. At mini- mum, companies should use voluntary clinical trial registries, such as those set up in the UK and pioneered by the Association of the British Pharmaceutical Industry (London). And biotech drug makers should follow the major drug companies that have committed to making trial results public, especially GlaxoSmithKline, Merck (Whitehouse Station, NJ, USA; NYSE:MRK) and Eli Lilly (Indianapolis, IN, USA; NYSE:LLY), who are spritzing outtake a bow Eliot Spitzer, New York's attorney general?- on their own trial registry web sites.

\section{Partnering}

Investors know that a company makes more money when it owns a blockbuster cancer drug lock, stock, and ribosome rather than one for which they have sold all but rights to milestones and royalties. Ditto one they market unfettered in the United States or Europe than one they share or market only in a smaller country. Yet the biggest flaw in company websites is the failure to identify partners clearly and to provide the terms.

Investors should see clearly not only the drug and indication and its status, but also the partner and the arrangement. Why not: 'MiracleMAb, 50-50 worldwide revenue split with partner GodzillaPharm?' How very rare this is, with companies at most giving a grudging nod to the partner deep in supplemental text, a click or more away. One good example is from MedImmune (Gaithersburg, MD, USA; Nasdaq:MEDI) whose link for pneumoccocal vaccine (http://www.medimmune .com/pipeline/scvaccine.asp) reveals the company's terms with GlaxoSmithKline (Middlesex, UK; NYSE:GSK).

\section{The worst so far}

Human Genome Sciences (Rockville, MD; Nasdaq:HGSI) lacks a chart, and pipeline information resides in a section misleadingly entitled 'Products.' Note to company: you have no products yet, only candidates.

The web is easy and cheap, so why don't all biotech drug makers strive to be the best? 